\title{
A Violência no Brasil. Causas e recomendações políticas para a sua prevenção
}

\author{
Violence in Brazil: causes and politic \\ recommendations to its prevention
}

Jean Claude Chesnais 1

1 Instituto Nacional de Estudos Demográficos, Universidade de Paris, França.

chesnais@ined.fr

Organizadora: Maria da Conceição N. Monteiro

Tradutora: Ida Maria

Rebelo Pereira
Abstract This article is about the kind of violence that happens in Brazilian main urban centers. It derived from a field research with visits and interviews with different individuals linked, directly or indirectly, to the subject such as employees and representatives of public sections of several areas, researchers and specialists, convicts and people involved in the drug traffic, as well as community leaders. It presents a wide diagnosis of the main factors that make possible the growth of criminal violence in Brazil such as social and economic factors, weakness and lack of confidence in the institutions and the difficulty of the state to avoid and prevent violence. The collected data allowed an analisis of the phenomenon in Brazilian reality, compared with other international urban centers. The political recommendations, based on the observation of the evolution of other countries, strongly point to the establishment of credibility of the state, starting from redistribution of income; great investiment in social areas, mainly health and education, and restructuring of their fundamental institutions as police and school.

Key words Violence; Criminality; Politic of Prevention
Resumo Este artigo trata da violência nos principais centros urbanos do Brasil. Foi originado de uma pesquisa de campo com visitas e entrevistas com diferentes indivíduos ligados, direta ou indiretamente à questão, como funcionários e representantes de setores públicos de várias áreas; pesquisadores e estudiosos do tema; presidiários e pessoas ligadas ao narcotráfico, bem como líderes comunitários. Apresenta um amplo diagnóstico dos principais fatores que possibilitam o crescimento da violência criminal no Brasil, ou seja, fatores sócio-econômicos, conjunturais e estruturais, a fraqueza e descrédito das instituições e a carência do Estado para administrar a repressão e propiciar a prevenção. Os dados coletados permitiram uma análise do fenômeno na realidade brasileira comparada com outros centros urbanos internacionais. As recomendações politicas, baseadas na observação da evolução de outros países, são fortemente dirigidas ao restabelecimento da credibilidade do Estado, a partir da redistribuição da renda; do grande investimento nas áreas sociais, sobretudo de saúde e educação; e da reestruturação de suas instituições fundamentais, como a polícia e a escola.

Palavras-chave Violência; Criminalidade; Política de Prevenção 


\section{A escalada da violência criminal no Brasil}

No Brasil, a violência, sobretudo urbana, está no centro do dia a dia e ocupa as manchetes dos jornais. Ela é assunto de especiais para a tv e, mais que tudo, assombra as consciências, de tal forma é ameaçadora, recorrente e geradora de um profundo sentimento de insegurança. Essa evolução é sintoma de uma desintegração social, de um mal-estar coletivo e de um desregramento das instituições públicas.

Assim como a Colômbia, lamentavelmente conhecida pela carência de um Estado forte e sobretudo pelas chacinas perpetradas pelos cartéis da droga (Medellin, Cali), entre os países de colonização européia, o Brasil é o mais atingido pela criminalidade assassina. $\mathrm{O}$ que se conhece é apenas a ponta do iceberg.

A violência oculta atrás dos muros das casas, a violência sexual, as rixas familiares e as crianças espancadas só são conhecidas muito parcialmente, mesmo em caso de falecimento das vítimas; as circunstâncias das mortes são, então, esmagadas sob uma capa de silêncio. Além do mais, o controle pelo registro civil continua a ser falho, principalmente nas zonas rurais mais pobres ou dentro de zonas urbanas de instalação recente (subúrbios, favelas e cortiços). O enterro oficial tem um custo com o qual as camadas mais desfavorecidas da população não podem arcar.

A situação atual no Brasil é, sem dúvida, atípica. As mortes violentas são a primeira causa de falecimento entre os 5 e 45 anos. Essas mortes prematuras, além de evitáveis, são altamente onerosas em termos de anos de vida perdidos. O homicídio intencional é, entre os homens, a primeira causa de óbitos em termos de potencial de vida perdido. A situação no Brasil é mais grave que nos Estados Unidos (EUA) e mesmo que na Rússia, mergulhada no caos, numa deterioração e numa criminalidade mafiosa indescritíveis desde a derrocada do comunismo.

Para estudar a especificidade brasileira, contatamos interlocutores mais informados e abertos, entrevistamos elementos dos mais variados meios (policiais, juizes, guardas penitenciários, detentos, delinqüentes, médicos legistas, responsáveis políticos, especialistas, jornalistas, diplomatas, empresários, trabalhadores sociais, etc.) e nos locais mais variados (escolas, hospitais, cemitérios, delegacias de polícia, escolas de tiro, penitenciárias, institutos médico-legal, favelas, etc).
Como qualquer visitante, para além do âmbito da nossa missão, ficamos chocados pela obsessão com a insegurança que atinge a totalidade dos habitantes das grandes cidades brasileiras. No centro de São Paulo, casas vigiadas, cercadas por grades, protegidas por seguranças, são igualmente sinais desta desconfiança das classes burguesas com relação às classes ditas perigosas.

Tudo se passa como se os brancos tentassem reproduzir enclaves europeus, evitando o contato com descendentes de escravos ou com os imigrantes, fugindo da miséria no seu Nordeste natal. Muitos são os que ousam falar de um apartheid social pois, diante de tal segregação social, é inevitável lembrar daquela que existe em países com forte tensão entre negros e brancos, como os EUA, ou a África do Sul.

A violência gera o medo, mas este gera igualmente violência. Trata-se então de um círculo vicioso que se instala, uma psicose coletiva que é preciso romper a qualquer preço e cujos únicos beneficiados são certos lobbies da segurança, como as firmas de vigilância, as milícias privadas, as companhias de seguros, os esquadrões da morte, etc.

Assim, são atingidas a imagem e a reputação internacionais do Brasil. Esse imenso país de sonho e de riquezas fabulosas não consegue "decolar" como prometido. Muitos responsáveis estrangeiros que nele apostaram guardam da experiência uma certa amargura, tal é o desperdício, a corrupção e o corporativismo que neutralizam a iniciativa e o esforço de inovação.

Tendo em conta que a realidade ultrapassa os números oficiais, o número efetivo de vítimas de homicídios é, hoje (1995), da ordem de 35.000 a 40.000 por ano. Na região metropolitana de São Paulo (16 milhões de habitantes), somam-se mais de 60.000 mortes desde 1983, ou seja, mais baixas do que no exército americano no Vietnã (56.000 mortes, a maioria das quais em acidentes de transporte ou retirada de minas e não em combate propriamente dito). Uma tragédia que afeta centenas de milhares de pessoas.

Essa situação só faz agravar-se a cada ano. Nessa mesma região de São Paulo, em meados dos anos 70, contavam-se 800 mortes por homicídio a cada ano. De 1989 para cá, esse número ultrapassa 6.500, ou seja, oito vezes mais. Essa explosão da violência não está relacionada com o aumento da população, pois a taxa 
de homicídio foi multiplicada por seis entre 1975 e 1989.

Desde então, parece que a situação está mais ou menos estabilizada, ainda que haja um agravamento previsto para 1995. Nos concentramos, aqui, exclusivamente na mortalidade por homicídio voluntário, excluindo qualquer outra forma de violência; esta é, na verdade, a parte mais grave e também a melhor elucidada da criminalidade. Nessa área, o Brasil distingue-se radicalmente de outros países de colonização européia; a taxa de homicídio aqui é comparável à da Inglaterra na Idade Média.

No Brasil, o número de óbitos por homicídio, registrados como tal, era de 28.700, em 1989, o que corresponde ao dobro do mesmo índice nos EUA. Essa cifra foi subestimada e um cálculo mais verossímil gira em torno de 35.000 a 40.000. Nos EUA, onde os números são melhor conhecidos, essa cifra é bem menor: 25.000 , para uma população superior em 100 milhões (265, ao invés dos 165 milhões de brasileiros). Os números brasileiros são, igualmente, superiores aos da Rússia (25.000, em 1993), com uma população equivalente. $\mathrm{Nu}$ ma proporção de pelo menos 20 para cada 100.000 habitantes, a taxa de mortalidade por homicídio é duas vezes maior no Brasil que nos EUA onde nunca ultrapassou o limiar de 10, mesmo na época de Al Capone.

Se considerarmos os grandes países da América Latina - deixando de lado a Colômbia, onde a economia da droga ocupa um espaço desproporcional na atividade nacional e, em conseqüência, a guerra dos cartéis e a luta contra o crime alcançaram proporções sem precedentes - as taxas no Brasil são superiores em um quarto às do México e correspondem ao quádruplo das taxas argentinas.

O fenômeno é sobretudo urbano. Assim, no Rio, a taxa é avaliada em cerca de 60 ou seja, três vezes a média nacional; em São Paulo, é de 45. A comparação com as outras grandes metrópoles do mundo é perturbadora. No Rio, a taxa é semelhante à de Washington (70), cidade com forte predominância de negros e conhecida pela insegurança e por seus bairros violentos.

Cidades multiculturais, como Nova Iorque ou Los Angeles, apresentavam, em 1994, um índice de homicídios de 30, bem inferior ao da Grande São Paulo (45-50, em 1995), duas vezes menor que o do Rio (60). O paralelo com Buenos Aires (11 milhões de habitantes) é ainda mais chocante já que lá esse índice é de apenas 6 para cada 100 mil habitantes.

\section{Possíveis causas dessa explosão da violência}

As razões desse extraordinário recrudescimento da violência no Brasil são difíceis de esclarecer. Na realidade, há uma complexa constelação de fatores em jogo e propõe-se aqui um quadro analítico.

\section{Fatores sócio-econômicos}

A pobreza e a fome. Entre as camadas mais pobres da população, a subsistência é precária. Grande número de crimes são cometidos sob o império da necessidade. Esse tipo de crime desapareceu da Europa no século passado. A miséria conduz ao roubo e à prostituição. Uma cidade como Fortaleza, onde a taxa de emprego não acompanhou o crescimento demográfico, está contaminada pela prostituição infantil e pelo turismo sexual.

O desemprego ou a ausência de renda levam à tentação da ilegalidade, visto ser fácil, por vezes, conseguir ganhos astronômicos à margem da lei. As vantagens são grandes, confidenciou-nos uma autoridade policial do bairro mais pobre de São Paulo: "ser ladrão aqui é a melhor profissão. Sem necessidade de levantar cedo e deitar tarde, de se cansar nos transportes coletivos, de trabalhar duro. Pode-se juntar muito dinheiro rapidamente, comprar um carro último modelo, e sem pagar impostos... Todos o respeitam pois a população admira os esbanjadores, os emergentes, a ostentação e o consumismo".

Há um aumento das desigualdades e, sobretudo, da percepção das mesmas, devido à grande penetração da televisão. A televisão valoriza objetos simbólicos e exalta o consumismo; ela induz a desejar roupas, equipamentos, carros, lindas garotas, etc. Essas coisas estão, freqüentemente, fora de alcance, o que provoca uma frustração crescente, insuportável numa sociedade polarizada pela coexistência de uma oligarquia riquíssima (São Paulo é, depois de Nova Iorque, a cidade com maior número de jatos particulares) e de massas miseráveis.

A sociedade brasileira é uma das mais desiguais, uma das mais estratificadas que existem. Aqui se encontra a mais extrema pobreza ao lado da mais fabulosa riqueza. Continua sendo o país dos privilégios pois a recessão econômica diminuiu a mobilidade social. O 
excesso de riqueza ostentada é vivido por muitos como uma provocação, daí a tentação do roubo e do dinheiro fácil.

\section{Fatores institucionais: A omissão do Estado na prevenção e repressão da violência}

\section{A Prevenção}

A escola: "Abrir uma escola é fechar uma prisão", escreveu Victor Hugo. O sistema escolar brasileiro é notoriamente deficitário e tem se deteriorado a partir dos anos 80 . A pré-escola praticamente inexiste; a escola primária começa muito tarde, aos sete anos somente. As crianças ficam, com freqüência, entregues à própria sorte até essa época, pois a mãe também tem de procurar um salário para garantir a subsistência, uma vez que a moradia e a alimentação são muito caras.

O ensino público é um desastre: os professores, mal pagos e desmotivados, não fazem um bom trabalho de pedagogos. Um grande número de crianças só vai à escola para comer pois lhes é assegurada uma refeição. A escola não garante mais a transmissão dos conhecimentos básicos. Essa instituição não soube se adaptar ao ensino de massa, as aulas limitamse a quatro horas por dia, vinte por semana; no resto do tempo os jovens ficam na rua, na casa de vizinhos ou diante da televisão.

A droga já conseguiu infiltrar-se nas escolas públicas. Estima-se que em São Paulo, um quarto dos jovens já são parcialmente tóxicodependentes pois começaram a fumar, a beber ou a se drogar.

Somente o ensino privado escapa ao naufrágio, mas o preço é proibitivo. No estado de São Paulo apenas um, em cada dez jovens, vai para a escola particular no primário. O corte tem se acentuado entre o público e o privado; a segregação escolar amplia a segregação social e mesmo a classe média está perdendo a esperança de ascensão social para os seus filhos.

A moradia: ter um abrigo, um teto, confere um sentimento de segurança e dignidade. Atualmente a crise de moradia é patente. Além de oferta insuficiente e políticas prediais inadequadas (ocupação ilegal, expulsão, retomada pela prefeitura, aumento abusivo de preços), o custo de acesso à propriedade ultrapassa os recursos dos mais pobres, especialmente da nova leva de nordestinos, desempregados ou mendigos na maioria.

Os aluguéis, depois do Plano Real, atingiram um nível fora do alcance da classe pobre e mesmo da classe média. Apesar da solidariedade familiar e do dinamismo da "auto-construção”, o número de desabrigados cresce.

Essa população flutuante, desenraizada, é, ao mesmo tempo, ameaçada e ameaçadora além de ser facilmente manipulável pelos chefes da droga e do crime que dela se servem para o roubo, para a prostituição e para a venda de drogas.

Os meninos de rua são presa fácil de certos indivíduos sem escrúpulos que, em troca de "proteção", de um substituto de paternidade, os exploram em proveito próprio, pervertendo-os e os expondo à morte.

A periferia da grande São Paulo é onde as populações são mais vulneráveis e desvalidas. Trata-se do cinturão de pobreza, povoado de recém-chegados, vindos do Nordeste, empurrados pela fome, semi-analfabetos, sem qualificação, dispersos numa cidade ameaçadora, instalados de forma precária numa terra de ninguém, onde os serviços públicos são deficientes ou francamente inexistentes.

A saúde pública: o setor sanitário deixou de ser prioridade. A prefeitura de São Paulo prefere a construção civil, as obras públicas (pontes e viadutos) e os transportes ao investimento social. Nos hospitais há falta de equipamentos e remédios, as filas de espera aumentam; o preço dos tratamentos torna-se exorbitante; o orçamento da saúde foi cortado e, às vezes, até mesmo o dinheiro destinado à saúde é desviado por burocratas sem escrúpulos.

São precisamente os bairros mais necessitados, onde as doenças infecciosas e as patologias crônicas estão mais propagadas, que pagam a conta do desperdício. Esse sentimento de vulnerabilidade biológica modifica a percepção que se tem do próprio corpo e tende a diminuir o valor da vida humana gerando essa atitude de indiferença diante do sofrimento e da morte.

O aumento da mortalidade adulta masculina é um sinal alarmante que deveria incitar os governantes à prudência. O exemplo de países da esfera soviética onde os orçamentos foram cortados a partir dos anos 60, mostrou a que ponto a condição sanitária pode retroceder: na Rússia atual a esperança de vida para os homens é inferior à da Índia. 
Certos gastos não podem ser reduzidos impunemente, eles fazem parte dos fundamentos, isto é, dos alicerces que mantêm o equilíbrio da sociedade na sua integralidade.

A saúde é condicionante da esperança, da produtividade, do investimento e do desenvolvimento. Não é por acaso que, já em 1980, o Japão, rival dos EUA rumo à supremacia econômica mundial, detinha o primeiro lugar em longevidade média da população.

Os transportes públicos: comparado com o sistema metroviário de Paris, o metro paulista é muito curto, enquanto a sua população é dois terços maior e tem de percorrer o dobro das distâncias. O tempo gasto nos transportes é maior, o serviço mais complexo e os preços, em termos relativos, cinco vezes mais caros.

Para o morador da periferia, trabalhar no centro significa longas jornadas (levantar muito cedo e deitar muito tarde) cujas horas passadas no transporte esgotam o organismo e desorganizam a vida familiar.

Tal situação desencoraja o trabalho. É mais fácil sobreviver com o trabalho informal (vender cigarros, isqueiros e outros objetos de contrabando) ou com a delinqüência, que com um salário. O salário mínimo (130 reais) nem de longe cobre os gastos essenciais de um indivíduo - moradia, alimentação e transporte e nem, tampouco, de uma família.

\section{A repressão}

A polícia, a justiça e o sistema penitenciário não são respeitados. Os salários e os meios são insuficientes, daí a facilidade com que os funcionários são corrompidos. A polícia cuida preferencialmente dos assaltos a casas e a bancos ou de roubos de caminhões - onde os riscos financeiros são maiores -que dos atentados contra indivíduos, exceto, é claro, quando se trata do seqüestro de milionários.

Um membro da polícia militar tem um salário da ordem de apenas 600 dólares por mês para uma tarefa ingrata, desprezada e perigosa cujas conseqüências são uma alta taxa de suicídios e de abandono da profissão. Muitos policiais têm um segundo emprego, nas horas livres; alguns desenvolvem a prática de achacar ou se deixam corromper pelos traficantes. A sorte da polícia civil também não é melhor.

A polícia militar é considerada violenta, facilmente exposta ao ridículo e impune, pois é protegida por seus próprios tribunais; a ela é atribuída a quarta parte das mortes por homicídio em São Paulo.

A polícia civil tem, por sua vez, uma imagem social ainda mais sombria já que é invariavelmente qualificada de corrupta e desacreditada pela polícia militar. Se a violência e a corrupção são inegáveis, considerando-se as condições de trabalho e dos meios onde são recrutadas as forças da ordem, há que se evitar toda generalização apressada pois a maioria do pessoal é honesta e dedicada.

A existência de quatro polícias públicas, mal coordenadas e, freqüentemente, rivais, cria confusão. A polícia federal, a polícia civil, a polícia militar e a polícia municipal têm, em princípio, papéis complementares mas, na realidade, mal definidos, o que atrapalha a eficiência da atuação assim que começa um tiroteio.

Mesmo a justiça é lenta, ineficaz e inacessível ao cidadão devido aos elevados honorários dos advogados. Quanto aos juizes pouco familiarizados com regras de contabilidade, com as astúcias da informática ou dos crimes de colarinho branco, são fáceis de enganar e subornar.

As prisões representam um mundo ainda mais obscuro: em São Paulo, contam-se 62 mil detentos em penitenciárias e delegacias de polícia. Esses detentos vivem em condições de promiscuidade inimagináveis - há, por vezes, até 30 presos em uma cela de $25 \mathrm{~m}$-, com apenas três beliches - que não favorecem a reeducação. As fugas são freqüentes, principalmente entre os traficantes de droga e criminosos de alta periculosidade; é fácil comprar a cumplicidade de um guarda pois o preço de uma fuga ( 6 mil dólares) representa para ele um ano de salário.

Esse fracasso dos dispositivos de segurança pública gera o sucesso das polícias paralelas, mais eficazes, melhor remuneradas porém muito mais onerosas e, por isso, reservadas à classe alta.

\section{O recuo da igreja católica}

Detentora de grande influência nos meios rurais, no passado, a Igreja Católica encontrase, desde então, dividida, enfraquecida e afastada do povo. O vazio deixado por ela é preenchido por seitas cada vez mais numerosas, ricas e poderosas. Essas seitas prometem a salvação e o paraíso aos ex-católicos dispersos e mal integrados na vida urbana; oferecem uma 
mensagem de sonho e misticismo, paralela a um temor pelo apocalipse próximo.

Com o fim do regime militar, a Igreja perdeu o seu papel de defensora dos oprimidos e se afundou em conflitos internos - planejamento familiar, luta pelo poder - que arruinaram a sua credibilidade.

\section{Fatores culturais}

O Brasil é o lugar dos paradoxos, onde se presencia o choque de duas culturas: a cultura do primeiro mundo, da Europa rica e branca, e a cultura do terceiro mundo, pobre e negra. É certo que há miscigenação e que a separação entre negros e brancos não é como nos EUA, mas existem claramente dois universos diferentes e, socialmente, pouco integrados. As relações sexuais mistas não excluem a cisão social nem a discriminação em matéria de casamento, emprego ou moradia.

A sociedade brasileira é feita de uma curiosa mistura de latinidade e negritude, onde os contrastes e a discriminação social não tardam a se revelar por trás da informalidade, jovialidade e cordialidade. Para escapar à sua condição, o negro tem de ser rico e isso tornase tanto mais difícil na medida em que aumentam as barreiras entre os dois mundos e as diferenças de níveis de vida e mentalidade se aprofundam. Nas prisões e necrotérios, a população é, em geral, negra ou mestiça; nas universidades, ela é 95\% branca.

\section{A demografia urbana}

A explosão demográfica entre os anos 19501970 , juntamente com a queda da mortalidade infantil, traduz-se por uma pressão sobre as infra-estruturas e orçamentos, e por uma competição feroz por emprego, agravados pela recessão econômica dos anos 80 .

Durante o período 1950-1970, a América Latina tinha o crescimento demográfico mais veloz do mundo. O produto dessa onda de nascimentos está hoje na adolescência, idade muito conturbada. Essa população luta para sobreviver e, ao procurar um lugar na sociedade, abandona o campo vindo desaguar nas grandes metrópoles.

O caso da Grande São Paulo é um dos mais espetaculares da história urbana. Em 1895, sua população era de apenas 200 mil habitantes; um século mais tarde, em 1995, subiu para 16 milhões. Entre 1970 e 1995, o número de habitantes passou de 8 para 16 milhões. Mesmo se, ao longo dos anos 80 , o saldo migratório ficou negativo e o número de emigrantes maior que o de imigrantes - desindustrialização, controle de entradas, especulação imobiliária - o fluxo continua intenso. Por outro lado, a baixa idade dessa pirâmide e a alta fecundidade das periferias garantem um avanço demográfico contínuo.

Em muitos bairros da grande São Paulo a taxa de crescimento da população ultrapassa $4 \%$ ao ano e é, precisamente, nessas zonas que a taxa de homicídio é mais elevada. É, efetivamente, nas áreas de povoamento exógeno, onde a população de migrantes tem grande dificuldade de encontrar trabalho e moradia, que a polícia encontra as maiores dificuldades de controlar a escalada do narcotráfico e de outros crimes. Ao se especializar em centro financeiro e de serviços, e contar com tecnologia de ponta, São Paulo viu aumentar a exclusão das camadas menos qualificadas.

Entre 1950 e 1995, o Brasil, que tinha a população de uma potência média, passou a ter a população de um gigante demográfico: 53,4 milhões, em 1950 para 161,8 milhões, em 1995. Ou seja, os efetivos triplicaram em menos de meio século.

Ainda hoje, apesar de uma forte desaceleração, o ritmo de crescimento da população é superior à média mundial e, até 1980, ultrapassava o dos países do terceiro mundo. Esse índice de crescimento ficou em torno de 3\% ao ano durante o período 1950-1970 (ao invés de $2,2 \%$ observado em outros países pouco desenvolvidos) e, mesmo que ele tenha caído recentemente (2\% em 1980-1990) e ficado na média do mundo em desenvolvimento, sua velocidade continua difícil de gerir, pois se aplica a um conjunto muito maior e mais complexo que na sociedade passada.

A noção de limiar crítico deve ser lembrada aqui, principalmente no tocante ao número de jovens adultos na faixa etária de 15-24 anos. Trata-se de uma população em busca de identidade, que não é mais criança embora não totalmente adulta. Essa população está em busca de referências sentimentais, familiares, profissionais, residenciais, etc.

De que maneira, a sociedade brasileira, sacudida pelos choques econômicos, poderia absorver, suavemente, essa onda demográfica? Essa sociedade está, na verdade, em plena tran- 
sição demográfica, isto é, na fase histórica provisória de dilatação brusca de seu contingente e sob influência da queda da mortalidade.

Assim, no Brasil como um todo, a esperança de vida, ao nascer, passou de 50 anos, no início dos anos 50 para 65 anos, em 1995. Tal progresso é produto, em larga escala, da redução da mortalidade entre os jovens. A taxa de mortalidade infantil, ou seja, o número de mortes em recém-nascidos e crianças de menos de um ano, baixou de $135 \%$ para $55 \%$, em cada mil nascimentos, entre 1950-1995. Ao mesmo tempo, o risco de morte prematura, entre mulheres jovens, devido ao parto, caiu para um terço.

Entretanto, essa explosão urbana, que tinha engendrado um crescimento descontrolado e anárquico das periferias - sobretudo em metrópoles, como Rio e São Paulo - atualmente, está melhor controlada. A polarização do espaço diminuiu e as correntes migratórias se redirecionam para cidades com dimensões mais humanas.

\section{A influência dos meios de comunicação}

Os meios de comunicação e, em especial, a televisão, tornaram-se um quarto poder, a seguir ao Executivo, ao Legislativo e ao Judiciário. Não se pode negar que a televisão, hoje onipresente, forma as consciências, sobretudo num país onde a escola é fraca e, onde as crianças passam, diante da telinha, a maior parte do tempo livre.

Ora, a televisão faz, a cada dia, a apologia do dinheiro e da violência: os assassinos são apresentados como heróis dos tempos modernos. Há um monopólio dos produtores e uma ausência de controle dos consumidores, submetidos a uma enxurrada de imagens sangrentas. O império da mídia banaliza a violência.

Ainda que a televisão desempenhe um papel ambíguo - também é catártico -, as autoridades policiais concordam sobre a influência que têm os modelos, aprendidos em filmes e novelas, no comportamento dos adolescentes. Muitos lamentam a ditadura da audiência e seus efeitos desastrosos sobre o diálogo em família.

\section{A globalização}

O processo de globalização da economia tende a abolir a noção de fronteira. Dos dois lados do Atlântico, criam-se grandes mercados (União Européia, Alena, Mercosul) e fala-se de supressão das fronteiras "internas". Num país como o Brasil, que faz fronteira com dez países e tem milhares de quilômetros para proteger, essa evolução facilita a proliferação de atividades ilegais e do crime organizado - roubo de carros, narcotráfico, loteria, etc.

Com o fim das ditaduras militares e a derrocada do comunismo, os laços entre as diversas formas de crime foram reforçados. Milhares de homens, saídos das instituições responsáveis pelo controle da ordem, habituados à disciplina e ao manejo de armas, tiveram de retornar à vida civil. Com freqüência, esses indivíduos juntaram-se a organizações criminosas com importantes ramificações internacionais. Na seqüência, enormes estoques de armas, cada vez mais sofisticadas, entraram no mercado provocando uma queda nos preços e um maior acesso a armamento.

Paralelamente, a partir de meados dos anos 80, o narcotráfico alcançou uma amplitude dramática na região dos Andes - Bolívia, Peru e Colômbia - e, até mesmo o Brasil tornou-se um novo gigante da droga. Passou a ser não apenas país de trânsito para a cocaína, proveniente dos países vizinhos e exportada para Europa e EUA, mas, também, local de consumo.

O desenvolvimento do narcotráfico, num contexto de crise sócio-econômica, é essencial para explicar o aumento das disputas e assassinatos sangrentos entre quadrilhas. Um círculo vicioso se instala: roubo de automóveis (para desmonte e venda das peças), assaltos a bancos para a compra de alguns quilos de cocaína, bairros inteiros controlados por traficantes que os transformam em mercado de consumo da droga. Esse comércio é muito lucrativo e profundamente devastador pois gera um clima de guerra civil: rivalidade entre os chefes das bocas de fumo, tiroteios, blitz da polícia militar, acertos de conta entre policiais corruptos de um lado e íntegros de outro, "vendettas" familiares, etc.

Numa cidade, como Fortaleza, onde a cocaína está pouco presente, o crack ainda ausente e a qualidade da administração pública é relativamente boa, a freqüência de homicídios continua baixa. Nessa cidade, os assassinatos estão ligados com freqüência a circunstâncias 
banais: brigas em conseqüência do álcool e violência doméstica. A maioria das vítimas é morta com faca e não com arma de fogo; o crime permanece individual, artesanal.

Nas grandes metrópoles como Rio e São Paulo, ao contrário, a droga gera lucros imensos e mergulha centenas de milhares de jovens na toxicodependência e no crime.

A cocaína provoca perda da noção de espaço, tempo e distância, além de provocar alucinações visuais. O crack, ainda mais perigoso, leva à dependência imediata e a uma mania de perseguição geradora de pulsões agressivas incontroláveis. Nos dependentes de crack, a necessidade da droga leva ao roubo, à violência, ao endividamento e à prostituição e, em certos casos, à morte com Aids.

Os doentes são submetidos a um círculo vicioso de despersonalização total. O jovem, delinqüente ou menino de rua, vende pedras de crack nos sinais, recebe o dinheiro e o entrega ao patrão; mas se ele recusar-se a entregar o dinheiro da venda ou se endividar por ter se tornado também dependente, corre o risco de ser eliminado.

São Paulo é o mais atingido pelas drogas. Segundo um dos responsáveis da delegacia de entorpecentes, o número de viciados em crack chega a 150 mil. Se essa avaliação é correta, há urgência de providências pois essas pessoas estão condenadas à morte em pouco tempo.

Segundo um responsável da polícia local, a situação atingiu um ponto tal que, na parte sul da Grande São Paulo, onde o desemprego e a miséria são maiores, a droga é a causa de duas em cada três mortes, vítimas de arma de fogo, na maioria. Uma visita ao Instituto Médico Legal mostra que essas pessoas são, geralmente, mortas com perfuração do tórax por uma bala calibre 38 - a arma mais comum entre policiais e marginais - provocando hemorragia generalizada.

\section{Recomendações políticas}

$\mathrm{O}$ crescimento da violência reflete, em primeiro lugar, a crise do Estado. Só nessa circunstância há deterioração do Estado-Nação, enquanto representante do bem comum, repositório legítimo do direito e da força em nome do respeito à lei. Exatamente como acontece na Itália, na Rússia, na Colômbia, em Uganda ou no Zaire, onde as máfias locais tomam o poder e arruinam a credibilidade política das nações. É também nesses países que a situação econômica se deteriora e que as moedas são fracas.

Em contrapartida, em países com forte disciplina coletiva, como Alemanha, Suíça ou Japão, o homicídio é raro, a prosperidade bem estabelecida e a moeda é forte, o que torna desnecessário remunerar o capital com taxas de juros abusivas para atrair ou impedir a fuga de investimentos.

A violência se inscreve então num clima psicológico coletivo, cujos significado e preço são muito pesados. A instabilidade e o descrédito pagam-se caro, em dinheiro e em vidas humanas, ainda mais na fase atual em que os capitais internacionais nunca estiveram tão voláteis.

Quanto à escola com sua vocação para transmitir conhecimentos de base: leitura, escrita, cálculo, deve acrescentar o aprendizado do civismo, e da tolerância. Essa mesma escola deve, também, oferecer formações de qualificação profissional, sobretudo em trabalhos manuais (o número de trabalhadores manuais não é satisfatório).

Num país jovem, o aprendizado da cidadania é mais delicado que nas montanhas suíças onde gerações vêm se sucedendo, há mais de mil anos, nos mesmos vales, com condutas bem regradas, definidas pela experiência e tradição. O respeito a si mesmo e aos outros, e até o orgulho nacional, traduzem-se nos costumes, e no respeito à constituição, às leis e aos regulamentos. Casos tão diferentes como os do Canadá e de Hong Kong são a prova disto.

\section{Criação de um Conselho Superior de Audiovisual}

A televisão exerce uma enorme influência sobre a formação das mentalidades. Ora, esse meio de comunicação está longe de exercer o papel educativo que se poderia esperar dele, exceto entre os cidadãos melhor formados, que fazem um uso seletivo.

A televisão tem, é verdade, a imensa virtude de unificar o território veiculando a mesma língua, a mesma mensagem e as mesmas imagens sobre o espaço nacional. Mas ela tem o defeito de impor aos mais vulneráveis e, com freqüência, nas horas de maior audiência, um quadro fascinante mas sangrento; alguns sociólogos chegam até a falar de "telemassacre" quotidiano. Esse fato não é privilégio do Brasil, é praticamente mundial. 
O estudo do conteúdo dos programas televisivos num país como a França (onde as imagens são, todavia, menos sangrentas que nos EUA) mostra que o telespectador vê vinte vezes mais gângsteres do que crianças. Mesmo os filmes cômicos estão repletos de atos de violência. Não temos certeza de que o espetáculo da violência sirva de válvula de escape para a agressividade; as pesquisas criminológicas e a experiência policial levam, isto sim, a pensar o contrário.

O conteúdo dos livros escolares é conhecido, debatido, controlado e "educativo". Por que, então, o dos programas de televisão deveria escapar à definição de certas normas e a um controle de qualidade?

A televisão tem uma influência relativa no Brasil, maior do que em outros países avançados onde a escola é precoce e para todos. Em nome de quais princípios, um punhado de produtores de imagens pode impor suas normas na intimidade diária de milhões de lares? Por que haveria um monopólio dos produtores em relação à nação consumidora? Deve-se restabelecer o equilíbrio entre os interesses dos produtores - vender sensacionalismo - e dos consumidores - divertir-se e instruir-se. No atual estado, os consumidores são passivos, não têm voz; trata-se, então, de defender seus direitos como cidadãos.

Nas condições atuais, é forçoso reconhecer que, na falta de organização da opinião pública, há uma ditadura de fato sobre as mentalidades: a de um punhado de homens que controlam as grandes redes de televisão. Esse desequilíbrio entre os poderes é, não apenas, incompatível com o surgimento de uma democracia pluralista mas, pela importância ocupada pelas imagens de violência, gerador de medo, insegurança e perda de confiança.

\section{A reabilitação do Estado-nação}

O Estado moderno, herdeiro da civilização greco-romana, tem origem na Idade Média. Era a época em que, na Inglaterra, como na França, os príncipes impunham regras de funcionamento ao conjunto de territórios sob sua guarda.

Os soberanos impõem grupos intermediários especializados - tribunais, polícias - para resolver litígios entre indivíduos, famílias, aldeias e clãs. A justiça passa, assim, de uma célula de base, como a família ou a aldeia, para uma autoridade superior centralizada que encarna o Estado, isto é, a coletividade como um todo. Essa transferência de legitimidade no exercício da força, no direito a represálias, foi seguida de um recuo progressivo dos assassinatos e vinganças tradicionais.

Para encontrar, na história inglesa, uma taxa de homicídios comparável à do Brasil atual, é preciso retroceder à Idade Média. A comparação é pouco lisonjeira mas, ilustra a que ponto o clientelismo, o espírito mafioso e a cisão de autoridade entre os chefes da droga criaram o caos e minaram os fundamentos do contrato social no Brasil. O reinado das máfias constitui uma regressão, um retorno ao estado feudal e a própria negação da democracia, fundada na legalidade de fato dos cidadãos diante da vida.

A imagem do Estado deve ser mudada. $\mathrm{O}$ Estado não é o polvo descrito por certos neoliberais. As economias mais competitivas e melhor preparadas para assumir a revolução tecnológica do século XXI são as de países com forte coesão e boa administração pública das necessidades essenciais - de nada serve equipar os computadores se os problemas de base não são resolvidos.

A alta tecnologia só se implanta com sucesso onde os pré-requisitos de instrução, saúde e ordem pública estão assegurados. Um Estado incompleto é um Estado parcial; entre o Estado com funções reduzidas e o Estado tentacular e despótico das sociedades comunistas, existe uma via intermediária: a do Estado ideal, definido por Locke (1690) há pelo menos três séculos.

O liberalismo não corresponde absolutamente à caricatura que lhe atribuem certos pensadores neo-liberais. Por trás de privatizações descabidas dos bens públicos, o que esses pensadores pregam, na verdade, é o desmantelamento da própria estrutura que sustenta uma nação moderna.

A nação não é a república de proprietários que alguns extremistas liberais querem restaurar. Ela se funda sobre a noção de cidadania e de igualdade de direitos no acesso aos bens públicos essenciais - instrução, saúde, segurança, moradia e transporte.

O Estado existe para garantir o contrato social e reprimir o roubo; é ele o árbitro entre os interesse particulares. A intervenção do Estado deve, porém, limitar-se ao mínimo exigido para a gestão dos interesses comuns: cometer crimes e delitos é infringir as leis que 
regem o direito de cada um sobre si mesmo e sobre seus bens.

Esse retorno à concepção original de Estado Moderno se impõe a fim de restaurar a credibilidade nos pilares da república: a estatística, a polícia, a justiça, a escola, o sistema de saúde pública, de transportes coletivos, etc.

\section{A estatística}

A estatística não é apenas uma redução enfadonha - é, antes de tudo, um instrumento de avaliação e auxílio nas decisões. Em matéria de criminalidade, é graças a ela que se pode determinar áreas de risco. Ela permite, igualmente, identificar categorias de pessoas perigosas ou em perigo e, então, hierarquizar as prioridades e instalar dispositivos de vigilância policial. A existência de zonas "pardas" que escapam a qualquer controle do Estado, onde o crime acontece impunemente, é prejudicial ao respeito pela coisa pública.

Postos de observação valiosos como o IBGE ou o Seade, que fornecem aos governantes os indicadores de que necessitam para orientar suas escolhas, devem, certamente, ser reestruturados a fim de aumentar sua eficácia e utilidade. Essa reestruturação não deve, entretanto, ser feita com cortes de pessoal e material pois colocaria em perigo sua produtividade. A solidez de conhecimentos é a base da qualidade das escolhas dos dirigentes. O que é um navegador sem bússola?

\section{A polícia}

A polícia brasileira tem má fama e é alvo de descrédito. Em todas as camadas da sociedade, inclusive nos meios policiais, ouvimos repetidamente que a polícia civil é corrupta e a militar violenta. Trata-se, é claro, de uma generalização grosseira e é preciso levar em conta o ambiente de trabalho, a frustração profissional e os salários insuficientes para as necessidades de uma família.

Além disso, a corrupção, assim como a violência, só atingem uma parte minoritária desses grupos profissionais. Entretanto, o mal existe inegavelmente e tem um efeito desastroso, junto à opinião pública, para a imagem das forças da ordem. Esses defeitos têm razões históricas e econômicas objetivas, difíceis de apagar a curto prazo.

É certo que os desvios de alguns, ainda que numerosos, não devem manchar a imagem do conjunto da profissão. Ao longo de nossas andanças em cidades tão diferentes como São Paulo, Rio, Fortaleza e Belo Horizonte encontramos, nas delegacias e penitenciárias, homens notáveis, desinteressados, dedicados à causa pública e com um aguçado senso do dever de proteger a sociedade, ainda que ao custo da própria vida. Testemunhamos o desconforto, a insegurança, a miséria e a extrema precariedade das condições em que trabalham.

Em Belo Horizonte, por exemplo, onde o recrutamento e a formação psicológica da polícia são mais bem feitos, a violência é menos freqüente. A imagem da polícia, em sua natureza profunda, é que tem de ser mudada; ela não deve ser vista como parasita mas como instância intermediária da república entre os cidadãos, como defensora dos fracos contra os fortes, das pessoas honestas contra os marginais.

Torna-se urgente restaurar a imagem da função policial. Isso seria feito através de campanhas publicitárias mas, também, de um esforço de revalorização das qualificações. A imagem a ser divulgada é a de uma polícia "cidadã", a serviço do bem público.

Informação objetiva pode ser produzida pelos grandes meios e, sobretudo, pela televisão, denunciando, sim, os abusos da polícia mas mostrando, também, sua face oculta, mais discreta e desconhecida: a dedicação extrema de milhares de profissionais anônimos cujo papel é imprescindível para impedir uma "colombianização" da sociedade brasileira.

A revalorização da profissão só se torna exeqüível com a adequação das perspectivas de carreira, ou seja, das funções e salários relativos dos corpos policiais. Ao se saber rejeitada, desprezada e pouco instruída, a polícia não se sente segura de si e adota um comportamento de desafio e provocação. Tudo melhoraria com a redução desse mal estar.

O medo é gerador de violência, o diálogo, redutor. A conversa, a negociação e a diplomacia sempre foram substitutos ao uso da força. A idéia de uma "polícia cidadã”, com respeitabilidade, integrada nos bairros, trabalhando a serviço da comunidade local deve abrir caminho.

As carências funcionais e organizacionais da polícia pública levam à proliferação das “polícias” paralelas, privadas. Em São Paulo existe o triplo de vigilantes particulares (em bancos, companhias de seguro, imóveis, etc.) que de policiais civis ou militares e essa polí- 
cia paralela, muito cara, só atende a uma minoria da população.

Há, portanto, um sistema de segurança em duplicidade, contrário à eqüidade e ao espírito republicano. Temos, de um lado, os happy few, que dispõem de uma proteção segura e de outro, a grande maioria da população. Essa maioria é vítima de grande insegurança, com o sentimento de estar entregue à própria sorte ou, mais exatamente, submetida às regras cruéis dos grandes traficantes ou dos marginais locais - passividade, respeito à hierarquia estabelecida e a lei do silêncio.

A atual guerra entre as polícias é nefasta, prejudicial a todos. A coordenação e, a seguir, a fusão das polícias civil e militar deveria ser considerada. Tal reforma pode parecer utópica, considerando as resistências corporativas, mas o início da coordenação das instâncias dirigentes com resultados promissores, como no caso de Fortaleza, mostra o caminho a seguir.

$\mathrm{Na}$ luta contra o crime organizado, a reforma da polícia traria inúmeras vantagens: 1) redução dos custos; 2) aumento da eficiência; 3) modificações no recrutamento e na formação. Temos consciência de que não se pode evitar uma parte do recrutamento feita em áreas de criminalidade, para facilitar a infiltração, mas isso deve ser feito com prudência.

\section{A saúde}

É preciso devolver à saúde pública a prioridade no orçamento civil. O caso da União Soviética, onde o orçamento destinado à saúde foi reduzido em meados dos anos $60 \mathrm{com}$ a tomada do poder pelo lobby militar encabeçado por Brejniev e a corrida armamentista, deve servir de advertência. Esse país, que em 1965 tinha uma esperança de vida igual à do Japão, constata, trinta anos mais tarde, uma queda de mais de 15 anos nessa taxa - podendo chegar a vinte anos, entre os homens.

O enxugamento do orçamento social imposto pela política de "apertar os cintos" e pela pressão das autoridades monetárias internacionais em nome do ajuste estrutural - controle da inflação e do déficit público - não deve ser executado de maneira cega nem, muito menos, dispensar o esforço de um controle financeiro pelo Tribunal de Contas, que zela pela aplicação dos recursos votados. Em tempos de austeridade orçamentária, como os atuais, o desvio, a cada ano, de bilhões de dólares inicialmente destinados a investimentos sociais de base - como a saúde e a educação - caracteriza crime contra o Estado.

A perseguição aos tecnocratas venais é indispensável. Muitos hospitais são, na realidade, verdadeiros depósitos de moribundos, sem chances de tratamento. O Brasil está relativamente mal colocado com relação à esperança de vida e à sua progressão; é ultrapassado pelos Tigres Asiáticos que souberam implantar estratégias de desenvolvimento fundadas em certos princípios indispensáveis como investimento humano - esforço de formação, saúde pública, reforma agrária, sistema fiscal justo, etc.

No caso do Brasil, a redução de despesas com a saúde penaliza sobretudo os conjuntos habitacionais mais vulneráveis, as áreas "pardas” da periferia e os morros. Ora, é precisamente nas áreas mais frágeis que se concentra a maior parte dos homicídios. A precariedade das comunicações, a insipiência dos serviços de urgência - ambulâncias - e de traumatologia, têm efeitos desastrosos sobre a mortalidade e o equilíbrio moral das comunidades afetadas.

Essas comunidades são as primeiras vítimas do corte orçamentário e da falência financeira no município de São Paulo. Elas se sentem abandonadas, desprezadas e podem, em conseqüência disso, tornarem-se hostis, perigosas e mesmo, manipuladas por líderes carismáticos irresponsáveis que as incitem ao ódio, à violência e à revolução. Essa fase de exclusão não pode durar para sempre. Uma radicalização sub-reptícia já se manifesta, aqui e ali, em torno de alguns líderes negros.

Alguns cemitérios do sul de São Paulo lembram os cemitérios dos campos de batalha das guerras civis européias do século XX. Nesses cemitérios, os túmulos são, em sua maioria, de homens jovens, assassinados, entre 15 e 30 anos.

Essa maioria é composta por indivíduos que não tiveram na sociedade outra alternativa senão o trabalho informal - metade do total de empregos, no país - ou a atividade ilegal, para não dizer o crime. Eles foram abatidos por soldados da droga, esquadrões da morte ou policiais; presos nesse infernal círculo do vício, eram, ao mesmo tempo, assassinos e vítimas. Órfãos, crianças sem pai, jogados na rua, analfabetos ou semi-analfabetos, eles ignoram as regras elementares do civismo; viveram, desde a mais tenra infância, num universo brutal e impiedoso, onde o respeito e a hierarquia têm por base a violência e o ran- 
king do crime. Sempre estiveram mergulhados em condições de precariedade, física e material, extremas; como, para eles, a vida não tem valor - a deles ou a dos outros - não temem a morte; sabem que, nesse meio, muitos têm vida curta. O crime, a Aids, as drogas ou o álcool vão eliminá-los no limiar da vida adulta.

O próprio sistema penitenciário deve ser repensado e readaptado às exigências, atuais e futuras, caso contrário, será elevado o preço pago pela sociedade brasileira.

A elevação acelerada do crime organizado fomenta a formação de uma nova classe criminal recrutada entre os marginais, formada e aperfeiçoada pelo contato com criminosos profissionais nas celas das delegacias e, a seguir, nas grandes penitenciárias. Durante uma entrevista, um criminoso lançou de maneira brutal: "Na escola pública eu fiz o primário, na prisão preventiva, o secundário e, depois de várias passagens por Carandiru, fiz o curso superior. Tenho todos os diplomas da escola do crime, conheço minha profissão e sou respeitado".

\section{A educação}

O proveito econômico da formação de base em termos de crescimento e desenvolvimento já foi determinado e é, regularmente, enfatizado pelo Banco Mundial. Na sociedade do século XXI, os trabalhadores analfabetos ou semi-analfabetos estarão cada vez mais defasados: a mecanização, a automatização, a informatização e a globalização os marginalizarão e excluirão. Então, o papel da escola é preparar o futuro, formando e enquadrando os efetivos futuros.

A educação não deve limitar-se apenas à transmissão de conhecimentos fundamentais: leitura, escrita, aptidão à abstração matemática, conhecimento de línguas estrangeiras, etc. Ela inclui, também, o aprendizado de regras de comportamento em sociedade, do civismo, do respeito pelo outro, pelas instituições e pelas leis, o conhecimento dos direitos e deveres do cidadão, o incentivo à inovação e à vida associativa e política local. Essas matérias são, igualmente, dimensões essenciais da recuperação nacional.

A perda de prioridade pelo setor da educação, a partir do início dos anos 80, diz respeito, sem dúvida, à crise da sociedade e da economia brasileiras. O choque da globalização foi melhor tolerado pelos países mais solidários e preparados mentalmente, graças a uma maior adaptabilidade, fruto da qualidade da formação de base, para enfrentar a desestabilização gerada pela intensa concorrência. Como reaproveitar milhões de ex-agricultores, ex-operários e ex-empregados se eles não têm nem mesmo os rudimentos dos conhecimentos de base necessários?

Ora, o ensino público brasileiro é notório pela deficiência e pelo despreparo com relação às exigências do futuro. Os professores, cujos salários são irrisórios, não têm formação contínua, não conseguiram se adaptar à mudança do ensino de elite para o ensino de massa e sua função cívica - ensino das leis, da ética e de valores em geral - tende a desaparecer. Isso acontece exatamente quando essa função é mais necessária, devido à crise da família, da sociedade e ao caos intelectual e moral provocado pelo desregramento dos meios de comunicação.

A escola deve, então, redefinir prioridades políticas. A violência é fruto, mais da ignorância, que da pobreza. Quais são as referências do analfabeto numa sociedade de sinais, de símbolos e de códigos cada vez mais complexos? Como pode um governo, que prega a entrada no terceiro milênio pelo advento das novas tecnologias, conceber esse salto para a modernidade sem um investimento maciço em qualificação? A sociedade do futuro vai exigir maior flexibilidade e adaptabilidade que a do passado, o que requer uma sólida formação de base para o maior número possível.

\section{Uma redefinição do Estado}

Duas tentações extremas devem ser evitadas: a de tudo pelo Estado, que desabou com o comunismo e a de nada pelo Estado, mais na moda, mas igualmente perniciosa.

O neo-liberalismo atual consiste em se gabar das vantagens do Estado mínimo, isto é, em destruir, em última estância, o Estado, considerado como parasita, como um polvo burocrático e, em conseqüência, desmantelar os serviços públicos de base - educação, segurança, saúde, etc. É uma via sedutora pois, é flagrante o fracasso do comunismo, fundado sobre a negação do setor privado. O retorno do cripto-comunismo em vários países da esfera soviética, depois de um período de pseudoabertura, retarda a transição e desqualifica os países envolvidos.

Trata-se, então, de fundar novamente um Estado ideal, de maneira a permitir o equilí- 
brio entre a liberdade - do Estado mínimo e a igualdade - do Estado máximo. A busca de eficácia não deve sufocar o imperativo de eqüidade.

A comparação das performances econômicas nas últimas décadas não deixa dúvidas: o sucesso é dos novos países industriais (Coréia do Sul, Taiwan) e dos "tigres" de segunda geração (Tailândia, Indonésia). Todos esses países têm um governo forte, com uma administração pública robusta, eficaz, controlando a totalidade do espaço nacional na realização de suas funções vitais: a infra-estrutura - estradas, transportes aéreo e ferroviário, rede postal, telecomunicações, audiovisual, captação de recursos hídricos, construção de esgotos, etc. - e a valorização do capital humano - sistema de saúde, de ensino, de segurança.

Entre os inúmeros interlocutores - brasileiros e brasilianistas -, vindos dos mais diferentes círculos, a maior parte ressaltou a importância de sair do imobilismo, ligado ao corporativismo secular, que só interessa a uns poucos privilegiados e limita o impulso de inovação que leva a reformas estruturais. O que está estigmatizado é muito mais a falta de Estado ou sua inadequação - que o excesso. A palavra de ordem seria, em suma: um melhor Estado.

Um brasilianista de renome chegou mesmo a dizer que o Brasil precisava de uma terapia de choque para sair do terceiro mundo, algo comparável ao esforço japonês que se seguiu à derrota militar de 1945. Foi, com efeito, a ocupação americana que ditou as reformas institucionais indispensáveis para fazer deslanchar a economia - constituição, reforma agrária, modificação do sistema de saúde, de educação, de impostos, etc.

É inútil perder tempo com querelas teóricas sobre a função do Estado, a experiência fala por si mesma, além do mais, a sociedade brasileira tem problemas urgentes e concretos a resolver. O investimento social - saúde, ensino, segurança - é pré-requisito do investimento econômico.

A perda de credibilidade do Estado brasileiro é um círculo vicioso de onde se deve imperativamente sair ou o país ficará comprometido numa espiral infernal e sem saída.

A irresponsabilidade, a corrupção, o descrédito levam a déficits, a falências e a evasões de capital que só podem ser corrigidos com a elevação maciça das taxas de juros: o Brasil tem, hoje, as taxas de juros mais elevadas e atraentes do planeta. Mas esta situação arrui- na os bancos e endivida excessivamente as finanças públicas, levando a uma redução do orçamento social. O desinvestimento social, por sua vez, repercute sobre a violência, a criminalidade e, por isso, sobre os negócios.

De acordo com a fórmula alemã, inaugurada logo após a Segunda Guerra, o que falta inventar é uma economia social de mercado, com compromisso sutil entre o Estado e as forças de mercado.

Há bens públicos que não deveriam, em nenhuma hipótese, ser privatizados sob o risco de romper os frágeis termos do pacto social e de gerar a total perda de legitimidade das instituições. O discurso, bem difundido entre certos intelectuais, sobre a "violência institucional” encontraria então sua justificação plena e a ordem bárbara das máfias se imporia sorrateiramente, pela fraqueza do Estado e o desaparecimento do civismo, ou seja dos vínculos sociais.

\section{As reformas estruturais}

\section{A integração nacional}

O Brasil é o país das misturas, a única nação verdadeiramente universal, onde coexistem todas as grandes civilizações do planeta, mas é também, o país das desigualdades e dos extremos. As maiores fortunas vão de par com a mais abominável miséria.

Essa realidade prejudica a imagem do país. A nova doutrina internacional do desenvolvimento, proclamada em todas as cúpulas mundiais - Cairo, Copenhague, Pequim - é uma doutrina que incorpora o social. Os mais eminentes economistas do Banco Mundial tendem a privilegiar, daqui para a frente, objetivos como o crescimento "sustentado" - isto é, com redistribuição da renda -, o desenvolvimento "humano", a capacidade de eliminar a "pobreza de massa".

Um desenvolvimento, muito desigual como o que a aceleração da globalização tende a suscitar em todo lado, a partir do início dos anos 80, leva a reduzir e, mesmo, a eliminar a coesão da sociedade. Os países considerados como modelos são os que souberam aliar eficácia e eqüidade. Foi o caso, por exemplo, da Indonésia dos anos 80 que conseguiu implantar uma política de preços e salários, se abrindo ao estrangeiro ao mesmo tempo que se apoiava num Estado forte. 


\section{A responsabilização dos formadores de opinião e das associações locais}

Os intelectuais, universitários, jornalistas e pesquisadores não são, em geral, comprometidos com estudo de campo; seus conhecimentos sobre o mundo do crime são parciais e, com freqüência tendenciosos, daí os perigosos preconceitos que alimentam a desconfiança com relação aos representantes do Estado - policiais, juízes, guardas penitenciários, etc. - cujo quotidiano é ignorado.

A formação de associações locais - esportivas, culturais, religiosas - nas áreas de alta insegurança deve ser encorajada pois facilita a vitalização da trama social e reduz a ociosidade dos jovens. Reunir iniciativas comunitárias vindas dos movimentos de mulheres, médicos, professores, líderes "naturais", jovens, empregadores, autoridades morais e religiosas, pode constituir o equivalente dos comitês tradicionais de vigilância das civilizações clássicas; pode, sobretudo, exercer a dissuasão, um contrapeso eficaz face às gangues, especialmente onde a polícia não dispõe de meios suficientes.

A demanda de descentralização/municipalização é grande, tanto em termos de redistribuição dos poderes como de gestão das finanças locais. Constatamos a força dessas associações perto do Rio, em uma área da Baixada Fluminense, conhecida pelo nível de extrema violência. A população local se reúne, se organiza e se constitui como grupo de pressão, criando assim um contra-poder eficaz em relação ao poder oficial e aos poderes paralelos - narcotráfico - ao mesmo tempo.

\section{A luta contra a toxicodependência}

Em inúmeros países do ocidente, é hábito afirmar que o custo demográfico do consumo de drogas é baixo: a morte por overdose é, na verdade, rara, mas isso é ver apenas a ponta do iceberg. Muitas mortes em acidentes automobilísticos, por suicídios e por homicídio, sobretudo, podem ser imputadas à droga. A detecção de THC (tetrahidrocloreto) na urina das vítimas é prova disso. Na França, por exemplo, dos jovens vítimas de acidentes na via pública, um quarto são consumidores de maconha. O uso da droga cria um sentimento de euforia e uma perda de consciência da velocidade e das distâncias. A responsabilida- de do álcool nas mortes violentas é amplamente reconhecida, mas não a da droga.

Além disso, é preciso ter uma visão global da toxicodependência. Pesquisas levadas a cabo junto aos jovens mostram que os fenômenos de consumo de substâncias tóxicas são interdependentes, melhor dizendo, são com freqüência as mesmas pessoas fumantes-drogados-alcoolátras, como se fosse uma síndrome de autodestruição física.

Ora, os toxicólogos sabem que a associação álcool-droga produz perturbações graves no funcionamento do organismo humano alucinações, dormência, modificação do ritmo cardíaco, da respiração, da digestão, etc. Num país como o Brasil, o balanço exato da toxicodependência, em termos, ao mesmo tempo, de saúde pública e desequilíbrio da atividade econômica - assalto a bancos, roubo de carros, crimes, delinqüência, corrupção, insegurança - ainda está por fazer. E é, certamente, pesado.

A luta contra a toxicodependência supõe, antes de mais nada, uma profunda vontade política que se faça notar. Isso se efetivaria, portanto, através de uma pressão dos meios de comunicação e da opinião pública.

Ações de força como na Itália e na Colômbia não devem ser excluídas. Mesmo o Exército teria um papel pois há perigo a vista: ameaça contra a segurança interna e, freqüentemente, com cumplicidade externa. Há redes de criminosos que é preciso desmantelar, atacando os chefes e neutralizando seus depósitos de armas e munição.

\section{A revolução do ensino}

A estocagem de dados, a informatização, a centralização, as escutas telefônicas, a reconstituição de fluxos físicos, financeiros e bancários não podem ser feitas sem um trabalho sério de inteligência estratégica - campanha, detecção, identificação, sinalização e reconstituição do organograma das redes de mafiosos. Nos anos 70, foi a reorganização do BKA - Bundeskriminallamt - na Alemanha, que possibilitou acabar com a onda de atentados terroristas organizados pela Facção Armada Vermelha, sob as ordens de Moscou. Da mesma forma, na Itália atual, a tomada do poder pelos juizes, com o apoio da opinião pública, permitiu desmantelar a máfia siciliana.

O Brasil, como lugar de trânsito (e produção) da droga e de armas de fogo, tem de re- 
constituir igualmente as conexões com as redes estrangeiras e as ligações com outras máfias, sobretudo os cartéis dos países vizinhos - Colômbia, Bolívia, Peru - ou mais distantes - Itália, EUA, China, Rússia, Turquia, etc.

Sob essa ótica, uma colaboração com os serviços especializados da CIA, do Narcotics Intelligence Consumers Committee, da Interpol e do FNULAD (Serviço de Entorpecentes das Nações Unidas) é prioritária. Enfim, um registro nacional das armas de fogo deve ser implantado após uma revisão da legislação num sentido mais restritivo.

\section{O endurecimento da legislação sobre as drogas e as armas de fogo}

Mantendo-se as tendências recentes, cedo ou tarde, o Brasil estará numa posição comparável à dos EUA onde mais da metade das famílias estão armadas e um lobby poderoso será constituído em favor da autodefesa e da livre propriedade de armas de fogo.

A National Rifle Association é, juntamente com o lobby dos caminhoneiros e do Automóvel Clube, um dos lobbies mais poderosos dos EUA. Ela se opõe ao "guns control" e constitui o principal obstáculo na luta contra o crime organizado. Não é raro encontrar-se, em certos bairros perigosos de várias grandes cidades, na própria entrada ou junto aos muros das escolas, jovens adolescentes de 12 a 15 anos portando armas de fogo.

A regulamentação no Brasil deve evitar tal descontrole, tanto mais que sua situação social - grau de desigualdade, hiper-urbanização, desemprego em massa, marginalização crescente dos jovens, etc. - é, potencialmente, explosiva. O porte de arma deve ser estritamente proibido e a sua propriedade controlada mais severamente.

Enfim, a legislação sobre a toxicodependência tem de ser revista, não se pode punir da mesma maneira a vítima - consumidor - e o assassino - traficante. A hierarquia das penas deve ser reconsiderada, o código penal revisado, em função da profissionalização do crime, sobretudo entre o sub-proletariado urbano.

\section{A cooperação das polícias}

À globalização do crime deve-se responder com a globalização da luta contra o crime. O crime organizado entrou na era "hight tech" - telefones celulares, armas automáticas; é a vez da polícia alfandegária e dos serviços de informação fazerem o mesmo.

Os laços com as polícias dos países andinos - Colômbia, Bolívia e Peru - devem ser incentivados e dirigidos de forma a harmonizar as práticas e partilhar informações. Mas, é sobretudo a cooperação com os EUA que deve ser ativada a despeito da má vontade evidente de certos líderes brasileiros, hostis, devido à sua corrupção, a operações como a teledetecção de campos de droga e de aeroportos clandestinos na Amazônia.

Sob esse ponto de vista, uma vez que a violência tomou a dimensão de uma guerra civil latente, de uma "Ersatzkrieg", nada impede de se buscar apoio no exército para fazer guerra às drogas - neutralização dos bandos organizados, confisco dos depósitos de armas, controle e vigilância dos guetos, controle de documentos, prisões, etc.).

\section{A revalorização das funções do funcionalismo público}

A imagem do pessoal dos serviços públicos deve ser mudada e a moda do "privado", do dinheiro fácil, que fez furor no ocidente nos anos 80, já deu mostras de falência; seus custos são em termos de crescimento da pobreza, da criminalidade e da ruptura dos laços sociais. $\mathrm{O}$ que está em causa é o risco de eliminação de uma classe média ambiciosa, motivada e confiante. A história já provou, entretanto, que a prosperidade das nações está ligada a emergência dessa classe empreendedora.

Ora, o salário de um médico no setor público é da ordem de 10 mil dólares ao ano, o de um detetive, 8 mil dólares, o de um professor primário, apenas 6 mil dólares, enquanto que os preços são comparáveis aos dos países ricos, da América do Norte ou da Europa ocidental.

Grande número de funcionários são, então, levados a ter um segundo emprego, enquanto outros vendem seu silêncio, sua cumplicidade ou colaboração aos que dispõem de dinheiro sujo. Essa defasagem em relação ao setor privado é flagrante demais para não le- 
var ao abandono, à desmotivação e a uma desqualificação dado o baixo nível do recrutamento.

\section{Conclusões: A potencialização das capacidades brasileiras}

O Brasil tem uma imagem internacional ambígua, feita, ao mesmo tempo, de fascinação e de descrédito. O país é dotado de trunfos, naturais e humanos excepcionais, mas ele é mais conhecido por sua jovialidade que por sua credibilidade.

A famosa fórmula assassina já é, há muito, conhecida: "este país do futuro será sempre um país do futuro”.

É sabido que o Brasil pode, considerados seus recursos, sua criatividade e seu peso demográfico, alcançar, num prazo de três a quatro décadas apenas, o quinto lugar mundial em termos de potência econômica. Mas, para isso, tem de acabar com a sua reputação de eterno adolescente, incapaz de disciplinar suas pulsões.

O sucesso do esforço para o controle da inflação é, sob este ponto de vista, uma etapa essencial que deve ser consolidada. A restauração da sua credibilidade, entretanto, tem de ir mais além. É a noção do bem público e da perspectiva que deve ser posta como ponto de honra e almejada pelas novas elites. A corrupção e os desvios de fundos públicos devem ser sancionados de forma exemplar, ou seja, intensamente divulgados pelos meios de comunicação.

Por que há tão poucos de seus habitantes que se sentem orgulhosos de dizer que são brasileiros, enquanto americanos, alemães, japoneses, e etc., têm orgulho da nacionalidade que possuem?

Esse déficit na imagem internacional tem um preço muito elevado, incomensurável. É esse déficit que induz a uma volatilidade de capitais e faz subir os juros a índices surrealistas. Esses índices asfixiam os bancos, arruinam as empresas e os indivíduos - endividamento excessivo - comprimem os orçamentos públicos e sociais provocando, portanto, a decadência dos serviços públicos que estruturam a sociedade - infra-estrutura, escola, saúde, segurança, etc.

Restaurar a credibilidade brasileira - sobretudo através de sua moeda - é, portanto, a prioridade das prioridades. Vivemos uma épo- ca de predomínio da consciência planetária através dos meios de comunicação e, mais precisamente, de algumas agências de imprensa. Nesta época, um país como o Brasil, com tantas qualidades, cometeria um grave erro se perdesse, mais uma vez, a sua chance, ao ceder aos apelos da moda e esquecer que nenhuma nação foi bem sucedida ao tentar sair do subdesenvolvimento num clima de anarquia. A atualidade russa e a africana - Nigéria, Uganda, Zaire - nos faz lembrar disso a cada instante.

As perspectivas de crescimento só se tornam realidade quando fundadas na solidez do Estado, na estabilidade das instituições, em investimentos no futuro, e, assim, num ambiente de confiança a longo prazo. A estabilização da moeda - em harmonia com uma reforma fiscal - deveria restabelecer o otimismo dos investidores e contribuir para facilitar o retorno ao crescimento econômico.

O crescimento, por sua vez, deveria permitir a criação de novos empregos e a elevação do nível de vida. Essa elevação do nível de vida levaria a um aumento na entrada de recursos fiscais, a um saneamento das finanças públicas e a um restabelecimento das funções vitais do Estado. A evolução recente conduz a um nítido impasse: o custo da segurança global - pública e privada - no Brasil, está avaliado pela soma astronômica de 28 bilhões de dólares, ao invés dos 5 bilhões previstos no orçamento das forças armadas.

Os bancos, o comércio, as empresas de transporte e o cidadão comum gastam somas extraordinárias com investimentos em segurança - vigilantes, equipamento - e com planos de seguro. O resultado desses investimentos é duvidoso: agravamento da delinqüência e da criminalidade.

A restauração da autoridade do Estado permitiria atenuar a realidade e a psicose de insegurança o que deslocaria, progressivamente, os gastos com segurança para investimentos produtivos.

O Estado é a encarnação da República, isto é, dos interesses superiores da nação; é o principal responsável no processo de civilização dos costumes; é o protetor legítimo e o árbitro entre os conflitos que dividem os cidadão ou os grupos privados. Ao faltar com o respeito ao Estado expomo-nos à desordem e ao risco de explosão social.

Nas sociedades urbanas avançadas, a exigência por segurança é cada vez mais acentuada. A busca, individual, de segurança é enor- 
me e, talvez, excessiva em relação às possibilidades reais.

A globalização só faz reforçar esse imperativo de segurança. Isso se deve ao fato de que os autores, na área financeira, vivem num universo sem fronteiras onde é decisiva a imagem, veiculada pelos meios de comunicação, dos países e das megalópoles gigantes. O retorno a um clima de segurança tem, por isso, um valor incalculável em termos econômicos e financeiros.

\section{Referência}

Locke J 1690. Second Treatise of Government, livre 11. 